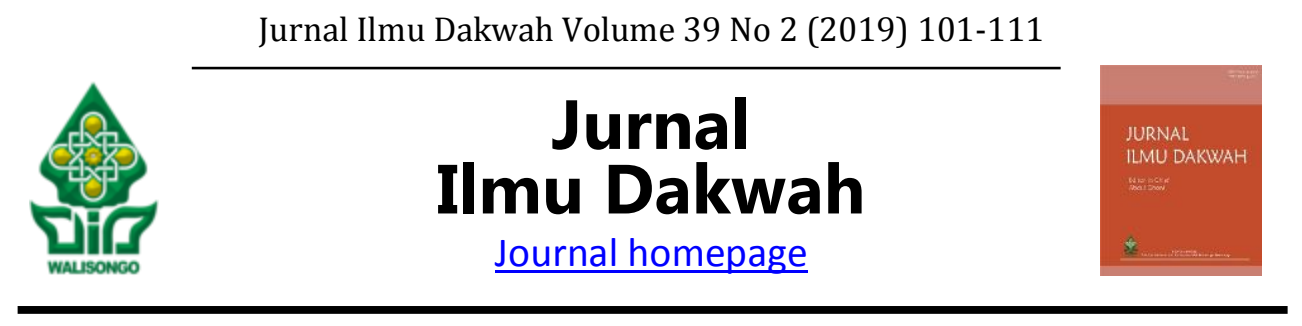

\title{
Paradigma Dakwah Kultural: Dimensi Sufisme dalam Kontruksi Karakter Bima pada Pewayangan Jawa
}

\author{
Dani Ata Vina1, Ahmad Hidayatullah² \\ 1Pascasarjana IAIN Salatiga, \\ 2Fakultas Ushuluddin dan Dakwah IAIN Pekalongan \\ Email: ahmad.hidayatullah@iainpekalongan.ac.id
}

\begin{abstract}
Wayang as a pride of Javanese culture is well known not only for artistic dimension, but also for a spiritual dimension. It can be seen from a compositions of wayang characters, namely Bima. This research is a qualitative research that focuses on library research about Mahabharata books, Javanese culture (wayang), Walisongo, and dakwah. This research is data analysis that uses descriptive analysis, as an effort to describe and analyze the siprirtiual dimensions are manifested in aspects of dakwah and sufism in the construction of the Bima character. The results of this study indicate that the character of Bima shows the construction for dimensions of dakwah and Sufism. The dimension of dakwah lies in the process of islamization of Hindu that contained in wayang that finally changes the character and storyline of the wayang itself. While the dimension of Sufism is in the process of conveying the values of Sufism, such as in the depiction of the soul (nafs) and manunggaling Kawula Gusti in the Dewaruci play.
\end{abstract}

Keywords: Puppet, Bima, Sufism, Cultural Da'wah

\begin{abstract}
Abstrak
Wayang sebagai budaya kebanggaan masyarakat Jawa, yang memiliki dimensi artistik dan dimensi spiritual. Hal ini bisa dilihat dari salah satu gubahan karakter wayang, yakni Bima. Penelitian ini merupakan penelitian kualitatif yang memfokuskan diri pada studi kepustakaan (library research) mengenai buku-buku Mahabharata, budaya Jawa (pewayangan), Walisongo, dan dakwah. Penelitian ini analisis data menggunakan analisis deskriptif, sebagai upaya untuk menguraikan dan menganalisis sejauh mana dimensi siprirtiual yang termanifest dalam aspek dakwah dan sufisme pada kontruksi karakter Bima. Hasil dari penelitian ini menunjukkan bahwa karakter Bima menunjukkan adanya konstruksi dakwah dan
\end{abstract}


sufisme. Dimensi dakwah terletak pada proses islamisasi ajaran Hindu yang termuat pada alur cerita wayang itu sendiri. Sementara dimensi sufisme terdapat pada proses penyampaian nilai-nilai tasawuf seperti pada penggambaran tentang jiwa (nafs) dan manunggaling kawula gusti pada lakon Dewaruci.

\section{Kata Kunci: Wayang, Bima, Sufisme, Dakwah Kultural}

\section{Pendahuluan}

Wayang merupakan seni pertunjukan yang sangat terkenal dalam berbagai bentuk di kawasan maritim dan daratan Asia Tenggara. Sementara di Indonesia, wayang hadir dalam beberapa bentuk, yakni wayang kulit, wayang golek dan wayang orang (Arps, 2007: 55). Di Indonesia, Jawa khususnya, wayang yang dikenal sebagai sebuah masterpiece (Sujarwo, 2010: xxxiv) kebanggaan masyarakat, tidak akan pernah terlepas dari nilai Hinduisme -yang berasal dari India- yang melatar belakanginya. Meskipun pada awalnya awalnya fungsi pertunjukan wayang adalah sebagai upacara keagamaan sebagai pemujaan terhadap nenek moyang kepercayaan Hyang yang merupakan budaya asli Indonesia (Dwi Andiyanta dkk, 2012: 96), namun Fakta perihal wayang sebagai sebuah karya adoptif ini disampaikan oleh Rassers yang menyatakan bahwa pertunjukan wayang di Jawa bukanlah ciptaan asli orang Jawa. Pertunjukan wayang di Jawa, merupakan tiruan dari apa yang sudah ada di India, utamanya dari segi pementasan yang menekankan pada seni memainkan bayang-bayang dari sebuah benda (Supriono dkk, 2008: 12).

Secara historis, setidaknya saat monarki Hindu-Jawa mulai surut pada awal abad ke-15, pengaruh Islam mulai masuk dalam kesenian wayang. Kenyataan ini wajar sebab keruntuhan kekuasaan Hindu terjadi salah satunya ditengarai oleh ekspansi Islam, meski faktor besar lain adalah adanya konflik para bangsawan Hindu-Jawa yang turut mempersuram masa depan kerajaan-kerajaan tersebut, semisal Majapahit (Sutiyono, 2013: 4). Raden Patah -yang seorang muslim- dalam hal ini seringkali dikaitkan oleh sumber lokal sebagai faktor runtuhnya Majapahit. Tetapi hasil penelitian mutakhir menunjukkan bahwa keruntuhan Majapahit lebih banyak karena konflik internal keluarga kerajaan. Kerajaan Bintoro Demak yang bercorak Islam inilah yang kemudian muncul para akhir abad XV bersamaan dengan surutnya Majapahit (Purwadi dkk, 2006: xv).

Fase awal kekuasaan Demak Bintoro ini kemudian juga menandai babak baru perkembangan wayang. Wayang sebagai sebuah media hiburan yang sudah begitu digemari masyarakat -baik anggota kerajaan maupun awam- pada era ini harus dihadapkan dengan kenyataan bahwa wayang dinilai Hinduistik, animistik, dan bahkan diharamkan karena tidak sesuai dengan ajaran Islam (Sudjarwo dkk, 2010: 51). Walisongo yang dalam sumber-sumber babad dianggap sebagai peletak pondasi terbentuknya pemerintahan Islam Kesultanan Bintoro Demak, tentu memberi perhatian khusus terhadap kesenian adoptif ini. Mereka menjadikan fakta tersebut sebagai tantangan sekaligus peluang dalam upaya untuk membumikan Islam di tanah Jawa agar masyarakat yang berada di bawah naungan Kesultanan baru ini tidak melenceng dari petunjuk Al Qur'an (Purwadi, 2006: xvi).

Fenomena di atas pada giliranya memunculkan konsekuensi logis tentang adanya dimensi simbolik dalam kesenian wayang. Pertemuan berbagai budaya, teologi dan ideologi membuat wayang mau atau tidak memiliki kandungan dari masing-masing unsur tersebut. Simbolisme budaya Jawa, Hinduisme dan Islamisme menjadi bagian yang tidak terpisahkan dari kesenian wayang baik secara subtantif maupun tersirat.

Kebrilianan para Walisongo itulah yang kemudian melahirkan gaya cerita dan modifikasi karakter tokoh wayang-wayang populer di tengah masyarakat Jawa. Dalam konteks ini Bima / Werkudara merupakan salah satu karakter yang 
representatif akan pernyataan di atas. Tokoh Bima dalam Dewa Ruci misalnya, merupakan sebuah contoh orang Jawa yang mencari air hidupatau hakikat diri dan memperoleh wirid dalam ilmu sejati dalam dirinya. Ia berhasil menemukan dirinya dalam dirinya sendiri (Dwiyanto, 2010: 54).

Penelitian sebelumnya tentang tokoh pewayangan Bima / Werkudara adalah penelitian Selu Margaretha Kushendrawati (2011), Wayang Dan Nilai- nilai Etis: Se buah Gambaran Sikap Hidup Orang Jawa. Penelitian ini mengungkap bahwa usaha Bima merupakan hal yang memang telah berakar dalam kehidupan manusia Jawa yang senantiasa tidak bisa dilepaskan dari pendekatan-pendekatan mistisisme. Wayang melalui karakter Bima pada akhirnya menjadi sarana untuk mencapai kesempurnaan melalui satu-satunya jalan bagi manusia untuk sampai kepada tujuan akhir yang disebut 'manunggaling kawula Gusti' (mystical union) (Kushendrawati, 2011: 107...). Penelitian ini mengungkap tentang tokoh Bima dalam aspek sufisme. Hal ini yang membedakan dengan kajian sebelumnya.

\section{Pembahasan}

\section{a. Bima sebagai Manifestasi Dewa Bayu pada Pra Islam}

Menurut mitologi Hindu, Bima merupakan manifestasi Dewa Bayu (Vayu). Di kalangan Hindu Bali sendiri Bayu merupakan salah satu dewa penguasa delapan arah mata angin, yang juga dikenal dengan Changkara dan wilayah kekuasaannya adalah arah barat laut (Sunyoto, 2012: 112). Sementara dalam pewayangan, ia juga sering disebut dengan nama Sang Hyang Pawana, yakni putra ke empat Sang Hyang Manikmaya dan Dewi Umayi. Kata Pawana berarti angin; Bayu berari kekuatan angin/penguasa angin.(Sudibyoprono,1991: 112). Selain itu ia juga dikenal sebagai dewanya kekuatan, dewanya hewan, raksasa dan manusia Aizid, 2012: 83). Ini wajar, karena dari postur karakter Batara Bayu sendiri merupakan sosok tinggi besar, gagah perkasa, dan menakutkan. Meski begitu ia memiliki kemauan dan pendirian yang jujur serta senang membela kebaikan (Yasasusastra, 2011: 26).

Dunia pewayangan menyebut ada sembilan mahluk yang dapat menguasai angin, yakni Batara Bayu, Anoman, Wil Jajahwreka, Liman (gajah) Situbanda, Nagakurawa, Garuda Mahambira, Begawan Maenaka, dan Dewa Ruci (Padmosoekotjo, 1979: 81). Ada pun tanda-tanda penguasa angin adalah berkain Dodot Poleng Bang Bintulu Aji dan berkuku Pancanaka. Kedua hal ini pasti dimiliki oleh mereka (Aizid, 2012: 83). Batara Bayu inilah ayah Bima yang sesungguhnya. Itu sebabnya Bima juga dikenal dengan nama Bayuputra, Bayusiwi, Bayutenaya, atau Bayusuta, yang kesemuanya merujuk pada arti: anak Batara Bayu (Sudjarwo dkk, 2010: 77).

Namun, menurut Bendung Layung Kuning, sebutan Bayusuta ini disebabkan untuk kekuatan Bayu yang menitis pada makhluk bumi. Oleh karenanya, kedelapan nama penguasa angin tadi adalah berjuluk Bayusuta (Aizid, 2012: 84). Mengenai lahirnya Bima, sebelumnya Pandu Dewanata memang tidak bisa mempunyai anak akibat sebuah kutukan yang didapatnya -dari seorang Brahmana-, maka ia meminta Dewi Kunti dengan ilmunya untuk mendapatkan putra dari Dewa. Kemudian dari anugrah Dewa Bayu inilah Bima dilahirkan (Haq, 2010: 96).

Bayu beberapa kali turun ke bumi untuk membantu anaknya. Semisal saat Bima lahir dalam keadaan terbungkus kulit ketuban. Batara Bayu merasuk dalam tubuh Gajah Sena untuk memecahkan pembungkus itu. Ia dengan kekuasaannya mendatangkan badai untuk menerbangkan pembungkus itu hingga ke pesisir Negeri Sindureja, yang kemudian dipuja menjadi Jayajrata (Sudjarwo dkk, 2010: 77).

\section{b. Dimensi Dakwah dan Sufisme dalam Karakter Bima}

Bima merupakan kesatria Pandawa yang memiliki peran cukup sentral dalam alur cerita Mahabharata. Sebagai tokoh protagonist, Bima kerap kali dimanfaatkan oleh para wali untuk menggubah banyak cerita guna menyisipkan berbagai pesan 
dalam rangka membumikan Islam di Tanah Jawa. Salah satu yang paling menarik dan begitu kentara sarat akan nilai-nilai Islam adalah Lakon Dewaruci.

Serat Dewaruci merupakan salah satu karya Sunan Kalijaga yang terkenal di masyarakat yang menceritakan Lakon wayang yang menggambarkan Bima mencari air suci Perwitasari Kayugung Susuhing Angin (Air Suci Perwita Sari, Kayu Besar Sarang Nafsu). Air suci diperlukan untuk dipersembahkan kepada gurunya, yaitu Pandita Durna, sebagai syarat agar Sang Guru mau mewejangkan tentang ngelmu jatining jejering pengeran (Soeparno dan Soesilo, 2007: 48).

Sebagai karya spiritual yang membahas seluk-beluk ilmu kebatinan, Serat Bima Suci (Dewaruci) juga mengungkapkan konsep moral yang bersifat etis-theologis. Serat Bima Suci menggambarkan Bima mempunyai gada Lukitasari yang merupakan lambang urat syaraf dan Aji Wungkal Bener yang melambangkan bahwa kehidupan itu batu pengasah kebenaran. Konsep Hinduisme kama-artha-dharma-moksa, dan konsep Islam syari'at-tarikat-hakikat-ma'rifat, keduanya dilampaui dengan harmonis oleh personifikasi tokoh Bima dalam Serat Bima Suci, sehingga memperoleh predikat 'insan kamil' atau manusia paripurna (Purwadi, 2005: 88).

Kisah Dewaruci ini menceritakan dan menggambarkan perjalanan Bima mencari kesempurnaan hidup. Ia dengan niat dan laku yang sungguh-sungguh, sentosa, kuat dan teguh pendiriannya serta tidak ragu, dapat menemukan guru sejatinya, yaitu 'Dewaruci'. Dalam perjalanan ini, Bima mampu menemukan jati dirinya, sehingga ia merupakan tokoh 'manunggaling kawulo gusti' (Soeparno dan Soesilo, 2007: 48-49). Dengan kata lain, dalam lakon Dewaruci lebih mencerminkan bahwa Bima sedang melakukan mawas diri (introspeksi diri) dengan tujuan menyucikan dirinya agar bersatu dengan-Nya (pamoring kawulo gusti). Terlebih cerita Bimasuci merupakan karya Jawa klasik yang menganjurkan mistik (tasawuf) dan tentunya, ajaran yang terkandung dalam lakon Bima Suci tidak bertentangan dengan monotheistis (Haq: 2010: 125).

Adapun secara rinci, lakon Dewaruci menurut Endraswara (2015) terbagi dalam delapan tahapan (episode), sebagaimana berikut: (Endraswara, 2015: 171173)

\section{Tahap pertama,}

Memuat kisah di gajah Oya. Duryudana sedang berdialog dengan Durna, tentang rencana pembunuhan terhadap Bima. Tiba-tiba BIma datang disambut dengan baik oleh keduanya. Ia diperintahkan untuk mencapai air suci mahapawitra dari sumur dorangga. Bima menjalankannya dengan sepenuh hati. Tanpa pikir panjang ia masuk ke sumur tersebut.

Atas perintah sang guru yang sangat dihormati, Bima ke sumur tersebut. Ia tidak menemukan air, melainkan sepasang ular naga membelitnya. Bima berhasil membunuhnya dengan kuku Pancanaka. Keduanya diruat menjadi bidadara dan bidadari yang tampan dan cantik bernama Sarambada dan Hamadi. Keduanya mengucapkan terimakasih kepada Bima. Bima kembali ke Hastinapura dan melaporkan kepada Drona. Ia dianjurkan ke hutan Amdadawa tempat keberadaan air suci.

Tahap kedua,

Berisi kisah bima menuju hutan Amdadawa. Bima tertipu lagi. Di hutan itu ia tidak menemukan air suci, melainkan berjumpa dengan raksasa Indrabahu yang ingin memangsanya. Terjadi perkelahian keduanya, dan raksasa berhasil dibunuh, raksasa mati, tetapi muncul Dewa Indra menjumpainya dan mengucapkan terimakasih karena telah meruwatnya. 


\section{Tahap ketiga,}

Bima mendapat punakawan ia mohon diri kepada ibu dan saudara-saudaranya. Karena ia dianjurkan ke dasar samudra tempat keberadaan air suci mahapawitra. Bima tenggelam ke dasar laut (akhirnya ia terdampar di sebuah pulau). Ia kagum melihat keindahan pulau tersebut. Berbagai macam tumbuhan dan binatang menghuni pulau tersebut. Sang Hyang Acintiya (nama lain Nawaruci) menciptakan berbagai macam makanan untuk menjamu Bima.

Tahap keempat,

Bima memndapat wejangan filosofis yang bertenden siwaistis, tentang arti hidup manusia. tujuannya, serta fungsi berbagai macam anggota badan dan hubungannya dengan kehidupan, tentang jenis kematian, sangkan-paran, dsb. Dalam memberikan wejang, Nawaruci minta agar Bima masuk ke dalam perutnya melalui telinga, setelah menerima wejangan secara tuntas, Bima mendapat nama baru, yaitu Awirota.

Tahap kelima,

Dengan nama Awirota, Bima meninggalkan Nusakambangan menuju Barunapada, tempat tinggal Sang Hyang Baruna, dan tertinggal dewa-dewa lain, seperti Brahmapada, Wisnupa Indrapada, dll. Selanjutnya ia menuju Amertajiwani di pertapaaan Siwamurti. Agar bisa masuk kesitu Bima harus mengalahkan penjaga pintu gerbang bernama Raja Panolah. Bima mendapatkan tirtakamandalu atau mahapawitra.

Tahap keenam,

Bima kembali ke Hastinapura untuk menyerahkan mahapawitra kepada Drona. Drona tidak percaya bahwa Bima berhasil mendapatkannya. Karena tujuan utama Drona bukan untuk mendapatkan air suci, melainkan ingin membunuhnya secara halus. Drona menghina Bima, Bima marah dan mendorongnya dalam laut, Bima tidak sampai hati melihat gurunya tenggelam lalu menolongnya.

Tahap ketujuh,

Bima meninggalkan Hastinapura menuju pertiwijati untuk bertapa, mengehningkan cipta dengan jalan menjauhi sesuatu yang bersifat duniawi dengan nama Angkuaprana. Bima mendapat restu dari para dewa, bahkan Sang Hyang Pramesthi Guru datang bersama Uma untuk merestuinya. Setelah memberikan berbagai macam godaan dan cobaan, Bima tetap tegar. Bima berdialog dengan paradewa tentang kebajikan dan kejahatan berdasar pada slokagama. Setelah itu Bima mendapat wejangan dari para dewa.

Tahap kedelapan

Bima berhasil mengalahkan godaan yang menimpanya. Ia juga meruwat Batara Guru dandewa-dewa lainnya. Para dewa menaruh hormat pada Angkusprana, lalu kembali ke kahyangan masing-masing. Bima kembali ke Indraprasta disambut oleh ibu dan saudara-saudaranya. Mereka mengadakan pesta pora untuk menyambut kedatangan Sang Angkusprana dengan kesaktian yang luar biasa.

Melihat gambaran ceritan di atas, dapat disimpulkan bahwa puncak dari kisah Dewaruci yaitu ketika Bima bertemu dengan wujudnya sendiri, penjelmaan yang Maha Kuasa. Bima dalam konteks ini berarti menemukan apa yang dicarinya sebagai 'air hidup', sangkan paran -asal-usul dirinya sendiri-. Dia mengungkapkan suatu pengertian dari dunia wayang itu, untuk memahami berbagai realitas usaha manusia untuk mencapai persekutuan dengan Yang Ilahi, sampai pada masalah kekuasaan (Haq, 2010: 124).

Tokoh Bima adalah salah satu Pandawa yang cukup mendapat ruang begitu besar dalam alur cerita wayang Jawa. Lakon Dewaruci menjadi media eksplorasi bagi Sunan Kalijaga guna menyampaikan teologi tasawuf sebagai sebuah jalan 
menuju kebenaran sejati. Sebagai karya spiritual yang membahas seluk-beluk ilmu kebatinan, lakon ini juga mengungkapkan konsep moral yang bersifat etis-theologis. Pada saat yang sama, proses besar desakralisasi juga terjadi di sana.

Sebagai titisan Dewa Bayu, justru Bayu sendiri yang menjadi sasaran untuk direduksi perannya 'sebagai Dewa' dalam lakon ini, di samping dewa-dewa lain tidak luput dari proses semacam itu. Adegan (episode) saat Bima yang harus bertarung melawan kelima saudaranya -se-titisan dengan Bayu- mulai nampak Bayu sedang ditempatkan dalam posisi yang 'kurang baik' dalam alur adegan tersebut, setidaknya secara istilah. Berikut adalah adegan di tengah-tengah Bima mencari sosok Dewaruci, menurut Efendi Zarkasyi (1996: 94).

Dalam perjalanan, Bima tidak lagi mengingat kebahagian kerajaan. Di perjalanan ia berjumpa dengan saudaranya 'tunggal baju' empat jumlahnya sehingga dengan ia sendiri berjumlah lima. Lima itu adalah: Pertama, Bayu Mangkurat, wujudnya kesatria, namanya Arya Sena; kedua, Bayu Kinara, wujudnya kera putih, namanya Anoman; ketiga, Bayu Kanitra, wujudnya gajah, namanya Setubanda, keempat, Bayu Anras, wujudnya burung, namanya Jajakwreka, kelima, Bayu Langgeng, wujudnya pendeta gunung, namanya Begawan Maenak. Semuanya membujuk kepada Arya Sena agar membatalkan sniatnya itu, karena mereka kasihan terhadap penderitaan yang akan dialami saudaranya itu. Tetapi arya sena teguh pendiriannya, maka terjadilah Pancakara perkelahian, Arya Sena dikeroyok empat orang.

Konteks tasawuf Jawa menyebut penggalan kisah ini sebagai gambaran orang yang rindu pada makrifatullah, walaupun sudah menjauhkan diri dari keramaian dunia, namun masih ada godaan-godaan, yaitu dari nafsunya sendiri. Malah kadangkadang nafsu ini tetap terus menggoda ketika orang berkhalwat. Efendi Zarkasyi menggambarkan kelima saudara Bima tadi digambarkan sebagai kelima nafsu, yang karakternya disesuaikan yakni (Zarkasyi,1996: 94-96):

Pertama, Nafsu lawwamah, seperti makan minum dll, maka dilambangkan dengan Begawan Maenaka, ialah Bayu Langgeng.

Kedua, Nafsu Sufiyah, seperti ingin melihat yang serba indah, mendengar serba enak dll. Lambangnya Gajah Setubanda, namanya Bayu Kanitra.

Ketiga, Nafsu Amarah, nafsu yang mendorong manusia jadi pemarah. Lambangnya, Burung Jajakwreka, namanya Bayu Anras.

Keempat, Nafsu Muthmainnah, ialah nafsu yang mendorong kepada kesucian, tetapi apabila menyeleweng (semuci-suci) justru menyebabkan dosa, lambangnya Anoman, ialah Bayu Kinara.

Kelima, Nafsu Mulhimah, ialah kekuatan Budi yang mendorong untuk melanjutkan sesuatu cita-cita. Lambangnya Sang Arya Sena, disebut Bayu Mangkurat yang memimpin Bayu yang lain.

Akhir adegan ini memang tidak menempatkan Bima (Arya Sena) sebagai sosok yang mampu mengalahkan mereka berlima -meski ilustrasi di atas menempatkannya sebagai pemimpin dari Bayu-Bayu yang lain-. Bahkan karena kuwalahan Bima lantas lari terus menuju ke laut untuk tetap bertemu Dewaruci. Hal ini membuat empat saudaranya bersepakat untuk tetap menolong Sena dengan cara menyatukan diri berwujud Gajah Setubanda dan rencananya akan menjadi kendaraan Sena ketika Sena mengarungi lautan (Zarkasyi, 1996: 97).

Gajah Sena yang kemudian mengetahui bahwa tekad Sena (Bima) adalah untuk terus melaju pada tujuannya, pada akhirnya marah dan membiarkan Bima tenggelam di lautan. Tahap ini disebut Zarkasyi sebagai representasi dari 'ngelem ing samodra urip/menyelam ke dalam samudra kehidupan' (Zarkasyi, 1996: 98). Meninggalkan keempat saudaranya itu sebagai wujud gambaran nafsu, dalam kisah 
ini ditampilkan sebagai sesuatu upaya meninggalkan hawa nafsu keduniawiyan untuk sebelumnya diakhiri dengan keberhasilannya bertemu dengan Dewaruci.

Bima dalam konteks ini berarti menemukan apa yang dicarinya sebagai 'air hidup', sangkan paran. Asal-usul dirinya sendiri. Dia mengungkapkan suatu pengertian dari dunia wayang itu, untuk memahami berbagai realitas usaha manusia untuk mencapai persekutuan dengan Yang Ilahi, sampai pada masalah kekuasaan. Dengan kata lain, dalam lakon Dewaruci lebih mencerminkan bahwa Bima sedang melakukan mawas diri (introspeksi diri) dengan tujuan menyucikan dirinya agar bersatu dengan-Nya (pamoring kawulo gusti) ((Zarkasyi, 1996: 124125).

Kisah di atas setidaknya memunculkan sebuah kesimpulan bahwa Bayu yang termanifestasi dalam kelima wujud putranya, hanya satu yang murni memiliki konotasi positif dari kelima hal tersebut, yakni nafsu mulhimah, sebagai kekuatan Budi yang mendorong untuk melanjutkan sesuatu cita-cita. Lambangnya Sang Arya Sena, disebut Bayu Mangkurat yang memimpin Bayu yang lain.

Nafsu mulhimah, atau terkadang dibaca malhamah menurut sumber lain merupakan nafsu yang letaknya berada di ' $r u h$ ', yaitu di bawah bagian payudara sebelah kanan kira-kira berjarak dua jari. Nafsu itu diwujudkan dengan sifat-sifat positif diantaranya derma, menerima, sabar, tawadhu', taubat, sabar, toleran. (AlJawi, 2006: 6). Sementara yang lain, digambarkan sebagai sisi negatif dari perwujudan nafsu itu sendiri. Atau singkat kata, Bayu yang dalam Hindu mutlak sebagai Dewa Penguasa Angin dan begitu sarat akan keagungan, dalam wayang perannya tidak lagi mutlak seperti itu. Ada sisi-sisi negatif sebagai sebuah komparasi dengan mahluk Tuhan bernama manusia.

Apalagi dalam ajaran Islam yang secara awam diketahui bahwa salah satu aspek yang membedakan antara 'setidaknya' malaikat -kalau mau itu ditafsirkan sebagai mahluk langit layaknya Dewa dalam teologi Hindu- dengan manusia adalah manusia memiliki nafsu, sedang malaikat tidak. Sementara wayang, menampilkan betul Bayu sebagai Dewa dalam manifestasinya sebagai unsur-unsur nafsu yang ada pada diri manusia.

Bukan hanya Bayu namun yang mengalami proses desakralisasi, Dewa-Dewa lain juga mendapat ruang desakralisasi dalam lakon Dewaruci ini. Hal ini terdapat pada bagian ke delapan dari kisah Dewaruci, seperti berikut: (Endraswara, 2015: 173).

\section{Tahap kedelapan}

Bima berhasil mengalahkan godaan yang menimpanya. Ia juga meruwat Batara Guru dan dewa-dewa lainnya. Para dewa menaruh hormat pada Angkusprana, lalu kembali ke kahyangan masing-masing. Bima kembali ke Indraprasta disambut oleh ibu dan saudara-saudaranya. Mereka mengadakan pesta pora untuk menyambut kedatangan Sang Angkusprana dengan kesaktian yang luar biasa.

Selain itu secara spesifik pada bagian kedua alur cerita, giliran Indra mengalami proses desakralisasi seperti berikut (Endraswara, 2015: 172)

Tahap kedua,

Berisi kisah bima menuju hutan Amdadawa. Bima tertipu lagi. Di hutan itu ia tidak menemukan air suci, melainkan berjumpa dengan raksasa Indrabahu yang ingin memangsanya. Terjadi perkelahian keduanya, dan raksasa berhasil dibunuh, raksasa mati, tetapi muncul Dewa Indra menjumpainya dan mengucapkan terimakasih karena telah meruwatnya.

Kunci perihal di mana terjadi proses desakralisasi pada adegan-adegan di atas adalah terletak pada kata 'meruwat'. Bima dalam adegan di atas digambarkan 
meruwat para Dewa, utamanya Dewa yang memiliki kasta tinggi dalam pewayangan -apalagi Hindu- yakni Batara Guru (Siwa). Perlu diketahui bahwa ruwat dalam dalam kamus Bahasa Jawa Kuna memiliki arti dibuat tidak berdaya, hancur, binasa (kejahatan, kutuk, pengaruh jahat), Sedangkan anruwat, rumuwat, rinuwat, yakni menyebabkan tidak berdaya, menghancurkan; membebaskan (dari kejahatan dll), membebaskan dari roh jahat (Zoetmolder dan Robson, 2011: 967).

Setidaknya kata meruwat memiliki makna mendekati dengan kata anruwat, yakni membebaskan dari hal-hal yang buruk yang membuat tidak berdaya seseorang. Jika dibenturkan pada konteks kebahasaan logikanya orang yang melakukan ruwat harus memiliki kemampuan lebih atas objek (orang) yang diruwat. Jika logika tersebut diterapkan, maka lagi-lagi tidak salah jika mengatakan ini sebagai proses desakralisasi pada karakter Para Dewa, sebab digambarkan mereka -setidaknya dalam kasus ini- berada satu trap di bawah Bima yang hanya seorang manusia.

Unikya proses yang sedemikian rupa wajarnya akan memantik konflik ataupun pergesekan antara pemeluk agama lama dengan para penyebar Islam, dalam hal ini para wali. Namun faktanya cara yang dilakukan para Wali, terutama Sunan Kalijaga begitu infiltratif sehingga tidak menimbulkan pergesekan di antara masyarakat. Hal ini merupakan efek domino dari sebuah pendekatan budaya yang secara hasil sangat signifikan terhadap perkembangan Islam, hingga kemudian Islam berkembang dengan pesat sampai kepelosok nusantara. Sisi persuasif pada akhirnya menjadi kata kunci yang menjadi salah satu daya tarik bagi setiap orang saat itu (Saputra, 2010: 62).

\section{c. Relevansi Sufisme Bima terhadap Dakwah Kultural}

Tidak diragukan lagi bahwa kontruksi pada karakter Bima dalam pewayangan Jawa merupakan satu dari sekian cara yang digunakan Walisongo dalam menginternalisasi nilai-nilai Islam di tengah masyarakat. Hal ini sekaligus menjadi sebuah capaian yang hingga saat ini belum terpecahkan oleh para juru Dakwah lain di belahan bumi Nusantara. Tinta emas sejarah akan terus mencatat dan mengabadikan mereka pada podium tertinggi sebagai tonggak tumbuh kembangnya Islam di Tanah Jawa, bahkan Nusantara. Pakar antropologi kenamaan Thomas Arnold (dalam Ismail dan Hotman, 2011: 253-254). menyebut model dakwah Walisongo ini sebagai lambang keberhasilan penyebaran agama Islam di Jazirah Melayu, terutama Jawa.

Sementara wayang menjadi salah satu kesenian yang menjadi saksi dan turut mengabadikan berbagai fakta tersebut. Melalui wayang -yang awalnya sempat dipertanyakan oleh sebagian anggota Walisongo sendiri perihal keabsahannya sebagai media dakwah sebab begitu sarat dengan aspek kesyirikan- Islam justru berhasil disampaikan secara infiltratif, humanis dan empatis kepada masyarakat Jawa yang sebelumnya memegang erat ajaran Hindu dan animisme-dinamisme. Desakralisasi, sakralisasi dan Islamisasi sebagai sebuah proses yang tidak mudah, sebab menyangkut keyakinan seseorang yang telah dipeluk sebelumnya, dengan tangan dingin para Wali mampu dilakukan dengan benda mati berwujud kesenian wayang. Alhasil, apa yang dilakukan oleh Walisongo melalui strategi dakwah kulturalnya terbukti efektif dalam meraih simpati masyarakat Jawa.

Menggunakan strategi dakwah kultural yang merupakan turunan dari penafsiran Islam yang bercorak kultural dan dinamis-dialogis (Ismail dan Hotman, 2011: 243). Walisongo menawarkan pemikiran yang objektif untuk membaca dan memaknai teks dan tradisi keagamaan. Sehingga Islam sebagai agama universal terbuka untuk dikontekstualkan dengan budaya lokal tanpa perlu takut kehilangan orisinalitasnya. Gerakan semacam ini dalam sesuai dengan pandangan Said Agil Siraj 
yang mengatakan bahwa tiga hal penting yang menjadi dasar penghayatan agama oleh setiap orang adalah: toleran, moderat, dan akomodatif. Semantara dewasa ini, corak tersebut malah sering mendapat tentangan dari minoritas muslim di Indonesia -yang cenderung konservatif- sebab tidak kesependapatannya dengan sinkreitisme yang dianggap sangat dekat dengan strategi ini.

Perbedaan semacam itu memang wajar adanya, sebab dalam praktiknya, di dalam masyarakat Islam terdapat dua kecenderungan dalam menyikapi kehidupan beragama, yakni: (Ahmad, 2016: 2-3)

Pertama, sikap insklusif yang dikedepankan masyarakat Islam dalam tradisi social-kemasyarakatan sebagai bagian dari kehidupan masyarakat. Sikap ini ditunjukkan dengan kerelaan untuk melakukan pergaulan sosial-kemasyarakatan, seperti bertetangga, berteman, bekerja, dan beraktivitas terhadap mereka yang berbeda agama. Pada cara pandang yang inklusif, seseorang akan cenderung menerima perbedaan, meskipun tidak sependapat dengan kebenaran orang lain, yakni sikap menerima yang toleran akan adanya tataran-tataran yang berbeda.

Kedua, sikap eksklusif yang dimiliki masyarakat Islam dalam menyikapi ritual keagamaan dan politik. Konsepsi ini pada gilirannya melahirkan sikap yang diskriminatif. Cara pandang yang eksklusif cenderung tertutup untuk menerima perbedaan, terutama dalam aspek teologi.

Bila berpijak dari dua sikap keagamaan di atas, Walisongo sejatinya sangat sejalan dengan sikap-sikap inklusif dalam mengadapi masyarakat Jawa saat itu. Apa yang mereka lakukan sangat sadar akan perbedaan dan kemudian menerjemakan dakwah mereka yang dalam redaksi Said Aqil Sirajd disebut sebagai toleran, moderat dan akomodatif. Setidaknya ketiga aspek tersebut sudah terwakili dengan cara Walisongo mengenalkan Islam kepada penduduk lokal dalam bentuk kompromi dengan kepercayaan-kepercayaan lokal yang mapan yang banyak diwarnai takhayul atau kepercayaan-kepercayaan animistik lainnya, tidak terkecuali terhadap mereka yang beragama Hindu. (Azra, 2002: 20-21).

Upaya para Wali membumikan Islam di Nusantara dengan cara-cara di atas tidak akan teraplikasi tanpa adanya sikap empatis mereka dalam menghadapi masyarakat Jawa saat itu. Sikap empatis sendiri merupakan sebuah kesanggupan seseorang melihat diri sendiri ke dalam situasi orang lain, dan kemudian melakukan penyesuaian. Dalam hal ini individu harus memiliki kepribadian mobil, yaitu kepribadian yang mudah menyesuaikan diri dengan situasi dan kondisi orang lain. Dengan demikian, empati dalam dakwah adalah sifat yang sangat dekat dengan citra seorang muballigh tentang diri dan tentang orang lain. Itulah sebabnya empati dapat dinegosiasikan atau dimantapkan melalui komunikasi antarpesona.(Arifin, 2011:7879).

Indikasi tersebut bisa terlihat saat Walisongo mencoba memahami karakter masyarakat Jawa pra-Islam, di mana dalam keyakinan mereka begitu sarat akan keyakinan Dewa dan mahluk ghaib. Kesadaran akan hal itu melahirkan kreatifitas dengan menggubah lakon-lakon baru di mana nilai Islam secara tidak kentara sedang diinfiltrasikan. Faktanya, tidak ada resisten akan hal ini yang meski jika diamati betul, ada sesembahan/Yang Kuasa mereka sedang direduksi kesakralannya secara perlahan, bahkan pada lakon tertentu diposisikan dalam karakter yang hinadina pada suatu alur cerita. Sebut saja Dewa Brahma yang berusaha membunuh cucunya Wisanggeni, Siwa (Batara Guru) yang mengutuk Uma karena tidak menghendaki hasrat seksualnya, Surya yang digambarkan seolah 'berhubungan gelap' dengan Kunti dan lain sebagainya. Kesemuanya itu, penuh dengan keyakinan jika diungkap dan ditampilkan pada era sekarang maka akan menimbulkan 
goncangan antar-pemeluk agama, bahkan bisa saja terjadi pertumpahan darah. Lagilagi secara realitas, para Wali justru menjadikan wayang sebagai tontonan apik yang membuat masyarakat Jawa kecanduan. Terbukti Sunan Kalijaga mendapat antusiasme yang begitu hebat saat melakukan pagelaran wayang kulit di berbagai daerah dengan didapatinya berbagai gelar dalang yang ia dapatkan dari masyarakat.

Kesemuanya itu muncul, menarik dan diikuti sebab sikap empatis yang para Wali terapkan dalam melaksanakan strategi dakwah kultural. Oleh karenanya tentu sangat tepat dan relevan apabila model dakwah berbasis kultural ala Walisongo untuk diterapkan dalam tatanan masyarakat di Indonesia dengan mengedepankan empati dalam upaya menerapkan pemahaman keagamaan yang toleran, moderat dan akomodatif. Kemudian inovasi dalam wujud kreatifitas dalam berbagai media dan aspek menjadi penting untuk diperhatikan, sebab pada hakekatnya memang manusia cenderung lebih senang dihibur ketimbang dinasehati. Sikap menggurui, mendekte, apalagi sampai menghakimi -jika ada yang dianggap salah- tidak akan menjadi magnet bagi intern umat Islam untuk semakin menjiwai dan mengaplikasikan ajaran rahmatan lin alamin ala Nabi Muhammad Saw. Terlebih bagi ekstern Islam, sikap semacam itu alih-alih memunculkan simpati, yang didapat justru respon anti-pati dan picingan mata terhadap nilai-nilai Islam yang sangat luhur dan agung.

\section{Kesimpulan dan Penutup}

Bima sebagai salah satu karakter populer dalam kesenian wayang kulit merupakan figur adoptif yang telah melewati transformasi dan inovasi dalam guabahannya. Pertimbangan teologis serta sosiokultur masyarakat Jawa pra-Islam membuat Walisongo yang dimotori oleh Sunan Kalijaga harus berinovasi dengan penuh kehatia-hatian. Ini karena kesalahan dalam menentukan langkah bisa jadi menimbulkan benturan di tengah masyarakat dan bukan tidak mungkin berujung pada pertumpahan darah. Alhasil wayang dalam bentuk barunya melahirkan dimensi baru yang belum pernah muncul sebelumnya dalam epos RamayanaMahabharata (notabene merupakan ajaran Hindu). Dimensi dakwah terletak pada proses islamisasi ajaran Hindu yang termuat pada wayang yang pada akhirnya merubah bentuk dan alur cerita dari wayang itu sendiri. Sementara dimensi sufisme terdapat pada proses penyampaian nilai-nilai tasawuf seperti pada penggambaran tentang jiwa (nafs) serta manunggaling kawula gusti pada lakon Dewaruci. Kesemuanya itu muncul, menarik dan diikuti oleh masyarakat sebab sikap empatis yang para Wali terapkan dalam melaksanakan strategi dakwah kultural. Oleh karenanya tentu sangat tepat dan relevan apabila model dakwah berbasis kultural ala Walisongo untuk diterapkan dalam tatanan masyarakat di Indonesia dengan mengedepankan empati dalam upaya menerapkan pemahaman keagamaan yang toleran, moderat dan akomodatif.

\section{Daftar Pustaka}

\section{Buku}

Arps, Bernard, 2007. Writings on Wayang: Approrches to Puppet Theatre in Java And Bali in Fifteen Recent Books. Indonesia Circle. School of Oriental \& African

Studies Newsletter: London.

Supriono, dkk, 2008. Pedhalangan Jilid 1. Jakarta: Departemen Pendidikan Nasional. Sutiyono, 2013. Poros Kebudayaan Jawa, Yogyakarta: Graha Ilmu.

Purwadi, dkk, 2006. Jejak Para Wali dan Ziarah Spiritual, Jakarta: Kompas.

Sudjarwo, Heru S., dkk, 2010. Rupa dan Karakter Wayang Purwa, Jakarta: Kaki Langit

Kencana Prenada Media Group.

Dwiyanto, Djoko, 2010. Ensiklopedi Wayang. Jogjakarta: Media Abadi. 
Aizid, Rizem, 2012. Atlas Tokoh-Tokoh Wayang, Yogyakarta: Diva Press.

Sudibyoprono, R. Rio, 1991. Ensiklopedi Wayang Purwa, Jakarta: Balai Pustaka.

Sunyoto, Agus, 2012. Atlas Walisongo. Depok: Pustaka IIMaN.

Yasasusastra, J. Syahban, 2011. Mengenal Tokoh Pewayangan, Biografi, Bentuk dan Perwatakannya, Yogyakarta: Pustaka Mahardika.

Haq, Muhammad Zaairul, 2010. Tasawuf Pandawa, Yogyakarta: Pustaka Pelajar.

Padmosoekotjo, S., 1979. Silsilah Wayang Purwa Mawa Carita Jilid. Surabaya: CV. Citra Jaya.

Soeparno dan Soesilo, 2007. Nilai-Nilai Kearifan Budaya Wayang. Malang: Yayasan Yusula,

Endraswara, Suwardi, 2015. Sejarah Sastra Jawa, Teori, Evolusi dan Transformasi. Yogyakarta: Ombak.

Zarkasyi, Efendi, 1996. Unsur-Unsur Islam dalam Wayang, Jakarta: Yayasan Mardikintono.

Al-Jawi, As-Syaikh Muhammad Nawawi al-Bantani, 2006. Qathrul Ghaits, Syarah Masail Abi al-Laits. Surabaya: Al-Haramain.

Zoetmulder, P.J. dan Robson, S.O., 2011. Kamus Jawa Kuna - Indonesia. Jakarta: Gramedia Pustaka Utama.

Saputra, Jhony Hadi, 2010. Mengungkap Perjalanan Sunan Kalijaga. Jakarta: Pustaka Media Press.

Idahram, Syaikh, 2011. Ulama Sejagad Menggugat Salafi Wahabi, Menegenal dan Mengkritisi Penyimpangan Tokoh-Tokoh Utama Mereka: Ibnu Taymiyah, Muhammad Ibnu Abdu Wahab, Nashirudin Al-Albani, Ibnu Baz, Ibnu Utsaimin, Shalih Ibnu Fauzan, dan lain-lain. Yogyakarta: Pustaka Pesantren.

Ismail, Ilyas, dan Hotman, Prio. 2011. Filsafat Dakwah "Rekayasa Membangun Agama dan Peradaban Islam", Jakarta: Kencana Prenada Media Group.

Azra, Azyumardi, 2002. Islam Nusantara: Jaringan Global dan Lokal. Bandung: Penerbit Mizan.

Ahmad, Rumadi, 2016. Fatwa Hubungan Antaragama di Indonesia, Kajian Kritis tentang Karakteristik, Praktif, dan Implikasinya. Jakarta: PT. Gramedia Pustaka Utama.

Arifin, Anwar, 2011. Dakwah Kontenporer, Sebuah Studi Komunikasi. Yogyakarta: Graha Ilmu.

\section{Jurnal}

Dwiandiyanta, B. Yudi, Antonius Bima Murti Wijaya, Martinus Maslim and Suyoto, 2012. New Shadow Modeling Approach Of Wayang Kulit. International Journal of Advanced Science and Technology Vol. 43, June, 2012.

Kushendrawati, Selu Margaretha, 2011. Wayang Dan Nilai- nilai Etis: Sebuah Gambaran Sikap Hidup Orang Jawa. Paradigma, Jurnal Kajian Budaya Vol 2, No 1 tahun 2011.

Purwadi, 2005. Dimensi Kearifan Lokal dalam Serat Bima Suci (Akulturasi Harmonis Ajaran Islam dengan Budaya Jawa), Jurnal Millah, Vol. V, No. 1, Agustus 2005, Yogyakarta: Program Pasca Sarjana Fakultas Ilmu Agama Islam Universitas Islam Indonesia. 